\title{
Effectiveness of Cognitive-Behavioral Therapy (CBT) on Quality of Life (QOL) and Worry in Patients with Generalized
} Anxiety Disorder (GAD)

\author{
Sheida Jabalameli ${ }_{1}$, Hamid Taher Neshat Doost 2 , \\ Mohammad Bagher Kajbaf 3 , Hossein Molavi 4
}

\begin{abstract}
:
Generalized Anxiety Disorder (GAD) is one of the most common anxiety disorders. It has been reported that psychological treatments like Cognitive-Behavioral Therapy (CBT) is effective for patients with GAD. The purpose of the present research was to investigate the effectiveness of CBT on Quality of Life (QOL) and worry in patients with GAD. A sample of 30 patients with GAD who had been referred to psychiatry offices in Isfahan, Iran were selected and assigned into an experimental group $(n=15)$ and a control group $(n=15)$ randomly. The experimental group received CBT in 8 weekly sessions. All participants completed the World Health Organization Quality Of Life-Brief (WHOQOL-BREF) questionnaire and the Penn State Worry Questionnaire (PSWQ) at pretest, posttest and follow up. The results of MANCOVA showed that the mean scores of QOL in the experimental group was significantly higher than the control group at the posttest and follow up $(\mathrm{P}<0.05)$ and the mean scores of worry in the experimental group was significantly lower than the control group at the posttest and follow up $(\mathrm{P}<0.05)$ It is concluded that CBT can be applied for the patients with GAD as a useful psychological treatment. In general, CBT can improve QOL and decrease worry in patients with GAD.
\end{abstract}

Keywords: Generalized Anxiety Disorder (GAD), Cognitive-Behavioral Therapy (CBT), Quality of Life (QOL), Worry.

\section{INTRODUCTION:}

Generalized anxiety disorder (GAD) is one of the most common anxiety disorders accounting for $12 \%$ of presentations at primary care clinics (DSM) (wells and carter, 2001). The lifetime prevalence of GAD in general population is 4-7\% (Allgulander et al, 2003).

\footnotetext{
${ }^{1} \mathrm{PhD}$ student of psychology, Department of Psychology, University of Isfahan, Isfahan, Iran. ${ }^{2} \mathrm{PhD}$ of psychology, Professor, Department of Psychology, University of Isfahan, Isfahan, Iran. ${ }^{3} \mathrm{PhD}$ of psychology, Professor, Department of Psychology, University of Isfahan, Isfahan, Iran. ${ }^{4} \mathrm{PhD}$ of psychology, Professor, Department of Psychology, University of Isfahan, Isfahan, Iran. unrestricted use, distribution, and reproduction in any Medium, provided the original work is properly cited.
} 


\section{Effectiveness of Cognitive-Behavioral Therapy (CBT) on Quality of Life (QOL) and Worry in Patients with Generalized Anxiety Disorder (GAD)}

Many researchers such as Palahang et al (1996) and Kavyani et al (2003) have been demonstrated that GAD is the most common anxiety disorder in Iran.

GAD is characterized by anxiety, tension, and chronic and persistent worry (APA, 2000). Worry is a central feature of GAD and it is experienced as excessive and uncontrollable (Wells and Matthews, 1996). The frequent and persistent worry and anxiety in GAD is out of proportion to the impact of the event or circumstance that is the focus of the worry (APA, 2000).

GAD is associated with significant distress and physical and psychosocial impairment (Kessler et al, 2004). The essential features of GAD include restlessness, fatigability, difficulty concentrating, irritability, muscle tension and sleep disturbances (Culpepper, 2002). In persons with GAD the prevalence of divorce and unemployment is more than the general population (Roberge et al, 2004). These factors may affect the Quality of Life (QOL) and its domains.

QOL is the general well-being of individuals and societies. QOL has a wide range of contexts, including the fields of international development, healthcare, politics and employment. QOL should not be confused with the concept of standard of living, which is based primarily on income. Instead, standard indicators of the QOL include not only wealth and employment but also the built environment, physical and mental health, education, recreation and leisure time, and social belonging (Gregory et al, 2009., Nussbaum \& Sen, 1993).

WHO defines QOL as individual's perception of their position in life in the context of the culture and value systems in which they live and in relation to their goals, expectations, standards and concerns. It is a broad ranging concept affected in a complex way by the person's physical health, psychological state, level of independence, social relationships, personal beliefs and their relationship to salient features of their environment. The persons with GAD have a lower QOL than the general population. The problem is often lifelong and only $50 \%$ of patients improve (Fisher \& Durham, 1999). Because of the chronic course of GAD, it is unlike to remit without treatment (Yonkers, 1996).

Effective treatment of GAD can be achieved with both pharmacological and nonpharmacological approaches (Culpepper, 2002; Gorman, 2003). Although the response to pharmacological treatment among subjects with anxiety disorders is rapid, but the high rate of relapse (Fava, 2005) and a lack of data about long-term wellbeing of patient are the main problems of this treatment (Roy-Byrne et al, 2005). It has been shown that two thirds of patients remain symptomatic after pharmacological intervention (Clark \& Fairburn, 1997). In the few last 


\section{Effectiveness of Cognitive-Behavioral Therapy (CBT) on Quality of Life (QOL) and Worry in Patients with Generalized Anxiety Disorder (GAD)}

decades attention has been paid towards psychological treatments (Brown et al, 1994). Many studies have been showed that psychotherapy is a reliable alternative to pharmacotherapy in order to decrease anxiety. According to several findings psychological treatments such as Cognitive-Behavioral Therapy (CBT), Metacognitive Therapy (MCT), Psychoanalysis and biofeedback can be more effective than pharmacological treatments for patients with GAD (Rygh \& Sanderson, 2004). Cognitive Behavioral Therapy (CBT) has been applied effectively to a wide range of mental-health problems and is the most common psychological treatment for GAD (Borkovec et al, 2003). CBT is a psychotherapeutic approach based upon a combination of basic cognitive and behavioral approaches. CBT is based on the principle that psychological distress results from distortions and biases in the way an individual interpret events. These give rise to negative meanings and maintain and strengthen unhelpful beliefs. In addition the way an individual behaves can generate problems by interfering with effective problem solving, by disrupting self-regulation and by preventing exposure to corrective learning experiences. For example, avoidance of a feared object prevents a person discovering that the object presents no real danger and erroneous beliefs about harm remain unchanged and anxiety persists (Faramarzi et al, 2008). In CBT the therapist works with the client to examine and modify negative thoughts, biases and behaviors that underlie symptoms. Homework is a part of treatment and often consists of recording thoughts, changing patterns of behavior, activity scheduling, and conducting 'behavioral experiments to test distorted beliefs. CBT involves variety of techniques in order to decrease anxiety such as relaxation, systematic desensitization, cognitive restructuring, interpersonal skills, problem solving and etc (Rygh \& Sanderson, 2004; Borkovec et al, 2003). In relation to investigation and research about the effects of CBT on anxiety, it has been tried to use conducted researches as the scientific documents in this field. In recent years, the variety of studies has been shown the effectiveness of CBT on psychological disorders and decreasing anxiety and worry such as Leichsenring et al (2010) and Ladouceur et al (2007). In a reanalysis of data from six CBT outcome studies, Fisher and Durham (1999) reported a recovery rate across all treatments of $40 \%$ overall based on trait-anxiety scores (Speilberger et al, 1983). The researches which have been shown the effectiveness of CBT on QOL particularly in persons with GAD are less than which have been shown its effectiveness on decreasing anxiety. It seems that CBT can improve QOL through its cognitive and behavioral techniques. Therefore, the purpose 


\section{Effectiveness of Cognitive-Behavioral Therapy (CBT) on Quality of Life (QOL) and Worry in Patients with Generalized Anxiety Disorder (GAD)}

of the present research was to investigate the effectiveness of CBT on QOL and worry in patients with GAD.

\section{MATERIALS AND METHODS}

\section{Statistical population, sample and method of research}

An experimental design was presented with an experimental group and a control group which were assessed at three different times: pretest, posttest and two-month follow-up. The statistical population of this research included the patients with GAD referred to psychiatry offices in Isfahan, Iran. Entrance criteria were: (1) primary diagnosis of GAD; (2) older than 20 and younger than 60 years; (3) no psychotherapy received for GAD; (4) no evidence of mental retardation, personality disorder, psychotic disorders, severe mood disorder, alcohol or drug dependence and other disorders in Axis I that needed special psychotherapy or pharmacotherapy. Based on these criteria, 30 patients were selected randomly. All patients signed informed consent. All referred patients were screened with a version of Persian SCID-I \& II (Structured Clinical Interview for DSMIV Axis I and II disorders). At the end of the screening stage the patients were informed about the study. After screening and investigating of their situation for participating in the study, patients were assigned in two equal experimental group (CBT) and the control groups randomly $\left(\mathrm{n}_{1}=\mathrm{n}_{2}=15\right)$. Patients in experimental group received 8 group weekly sessions of CBT of 60-90 minutes duration. In each session the CBT techniques such as relaxation, systematic desensitization, cognitive restructuring, increasing clients' awareness of patterns of anxiety responding, function of emotions, interpersonal skills, problem solving and etc were used. Homework was a component of the treatment. Patients were also taught a variety of CBT practices and were encouraged to perform daily CBT practices. . After completing the treatment, all participants completed questionnaires in a joint meeting. After the two months of posttest, follow up test was conducted on both two groups. Control group remained on the waiting list until the end of follow up and then it received the same training.

\section{MEASURES}

\section{Demographic questionnaire:}

Demographic questionnaire has been designed by the researcher in order to control the variables of population such as age, sex, educational level, and marital status. 


\section{Effectiveness of Cognitive-Behavioral Therapy (CBT) on Quality of Life (QOL) and Worry in Patients with Generalized Anxiety Disorder (GAD)}

\section{World Health Organization Quality of Life-Brief (WHOQOL-BREF):}

This scale was developed by WHO in 2001, and has been translated and standardized in Iran. This scale consists of 26 questions, and examines the quality of life of the test-taker from different aspects through Likert 5-grade scale. Two questions are to evaluate the overall feeling of the person over his/her life quality, and the rest of the questions assess the feeling and behavior of the test-taker in terms of physical health, mental health, social relationships, and community health in a period of last two weeks. Each of these aspects is assessed by 7, 6, 3, and 8 questions respectively. In most studies, the validity and reliability of the scale have been reported as acceptable. Nejaat et al. have reported the reliability of the physical health subscale as $0.77,0.77$ for mental health, 0.75 for social relationships, and 0.84 for community health using retest method. In order to investigate the significance of the difference between and among different groups in the areas of brain/behavioral systems, and quality of life, by means of multivariance analysis test (MANOVA) using SPSS-16 software. The significance level of the findings was set $\mathrm{p} \leq 0.05$ (Najafi et al, 2014).

\section{The Penn State Worry Questionnaire (PSWQ; Meyer et al, 1990):}

The PSWQ is a16-item measure that assesses the generality, excessiveness, and uncontrollability of worry without focusing on particular domains of worry. The reliability and validity of the PSWQ have been widely researched, and the instrument appears to have sound psychometric properties (Molina \& Borkovec, 1994). This well-established measure of worry has been shown to have very good reliability ( $\alpha$ of .86 to .93 ) and good test-retest reliability. It demonstrated adequate internal consistency at pre- $(\alpha=.77)$ and post-treatment $(\alpha=.92)$ (Brown et al, 1992).

\section{Data analysis}

Data analysis was done by SPSS version 16 software using MANCOVA. P-Value less than 0.05 were considered as significant. 


\section{Effectiveness of Cognitive-Behavioral Therapy (CBT) on Quality of Life (QOL) and Worry in Patients with Generalized Anxiety Disorder (GAD)}

\section{RESULTS}

Table 1 showed demographic characteristics of two control and experimental groups.

Table 1. Demographic Characteristics of Control and Experimental Groups

\begin{tabular}{|ll|l|l|}
\hline \multicolumn{1}{|l|}{ Variable } & CBT & Control \\
\hline Age (year): & Mean (SD) & $37.2(7.9)$ & $39.2(6.1)$ \\
\hline Sex: & Male: N (\%) & $6(40)$ & $5(33.4)$ \\
\hline & Female: N (\%) & $9(60)$ & $10(66.6)$ \\
\hline Marital status: & Married & $12(80)$ & $11(73.4)$ \\
\hline & Single & $3(20)$ & $4(26.6)$ \\
\hline Educational level: Middle school & $2(13.3)$ & $1(6.66)$ \\
\hline & High school & $4(26.6)$ & $5(33.3)$ \\
\hline & $9(60)$ & $9(60)$ \\
\hline
\end{tabular}

The means and standard deviations of the scores of dependent variables at pretest, posttest and follow up in the experimental group and the control group are presented in Table 2.

Table 2. Means and Standard Deviations (SD) of the Scores of QOL and Worry in Two Groups at Pretest, Posttest and Follow up

\begin{tabular}{|l|l|l|l|l|}
\hline Variable & Group & $\begin{array}{l}\text { Pretest } \\
\text { Mean (SD) }\end{array}$ & $\begin{array}{l}\text { posttest } \\
\text { Mean (SD) }\end{array}$ & $\begin{array}{l}\text { Follow up } \\
\text { Mean (SD) }\end{array}$ \\
\hline QOL & CBT & $71.3(5.4)$ & $82.2(6.1)$ & $81.3(5.3)$ \\
\hline & Control & $72.8(4.9)$ & $73.1(5.2)$ & $72.4(4.7)$ \\
\hline Worry & CBT & $61.2(5.4)$ & $53.2(6.1)$ & $52.4(5.7)$ \\
\hline & Control & $62.4(4.9)$ & $63.1(5.2)$ & $62.6(5.6)$ \\
\hline
\end{tabular}

Based on table 2, there appears to be large differences between two groups at posttest and follow up stages. The mean scores of QOL in the experimental group have been increased in posttest and follow up, while this increase is not seen in the control group. Also the mean scores of worry in the experimental group have been decreased at posttest and follow up, while this decrease is not seen in the control group. 


\section{Effectiveness of Cognitive-Behavioral Therapy (CBT) on Quality of Life (QOL) and Worry in Patients with Generalized Anxiety Disorder (GAD)}

The assumption of normality was not rejected by the Shapiro-Wilk test (P>0/05). Also, the equality of population variances was not rejected by Levine's test $(\mathrm{P}>0 / 05)$. The mean scores of dependent variables (QOL and worry) at pretest entered as covariate variables in MONCOVA model. Since conditions did not differ significantly in demographic characteristics, the MANCOVA was done without these variables. Analysis by MANCOVA used pretest scores as covariate variables effects on posttest and follow up.

The result of the analysis of covariance of the effect of group membership on QOL and worry scores is presented in Table 3.

Table 3. Analysis of Covariance of the Effect of Group Membership on Dependent Variables

\begin{tabular}{|c|c|c|c|c|c|c|c|c|}
\hline $\begin{array}{c}\text { Dependent } \\
\text { variables }\end{array}$ & Variable & $\begin{array}{l}\text { Sum of } \\
\text { Squares }\end{array}$ & df & $\begin{array}{c}\text { Mean } \\
\text { Square }\end{array}$ & $\mathbf{F}$ & Sig. & $\begin{array}{c}\text { Partial } \\
\text { eta } \\
\text { squared }\end{array}$ & $\begin{array}{c}\text { Observed } \\
\text { power }\end{array}$ \\
\hline \multirow{4}{*}{ QOL } & Pretest & 189.7 & 1 & 189.7 & 53.9 & 0.001 & 0.33 & 0.94 \\
\hline & Treatment & 1292.32 & 1 & 1292.32 & 129.32 & 0.002 & 0.51 & 0.94 \\
\hline & Pretest & 176.4 & 1 & 176.4 & 48.7 & 0.001 & 0.38 & 0.91 \\
\hline & Follow up & 1105.6 & 1 & 1105.6 & 111.8 & 0.001 & 0.42 & 0.91 \\
\hline \multirow{4}{*}{ Worry } & Pretest & 91.9 & 1 & 91.9 & 17.54 & 0.002 & 0.33 & 0.91 \\
\hline & Treatment & 944.12 & 1 & 944.12 & 77.8 & 0.001 & 0.54 & 0.93 \\
\hline & Pretest & 89.2 & 1 & 89.2 & 21.6 & 0.001 & 0.28 & 0.91 \\
\hline & Follow up & 837.63 & 1 & 837.63 & 96.3 & 0.002 & 0.45 & 0.89 \\
\hline
\end{tabular}

As can be seen in Table 3, CBT had a significant effect on QOL and worry scores. Group membership explained 51\% of variance of QOL scores and 54\% of variance of scores of worry 


\section{Effectiveness of Cognitive-Behavioral Therapy (CBT) on Quality of Life (QOL) and Worry in Patients with Generalized Anxiety Disorder (GAD)}

at the post test, which was statistically significant $(\mathrm{p}<0.05)$. Also, this result was maintained at two-month follow up. Group membership explained 42\% of variance of QOL scores and 45\% of variance of scores of worry at the follow up which was statistically significant $(\mathrm{p}<0.05)$.

\section{DISCUSSION AND CONCLUSION}

The purpose of this research was to investigate the effectiveness of CBT on QOL and worry in patients with GAD. CBT was considered as the independent variable. The dependent variables were anxiety and QOL. Given the significant effect of CBT at posttest and follow up, the results seem promising. Results demonstrated that subjects in the CBT group experienced a significant decrease in their anxiety and a significant increase in their QOL following an 8-week CBT. Therefore CBT techniques can decrease the symptoms of GAD and improve the QOL.

Our results are consistent with some previous studies such as Fisher and Durham (1999), Gould et al (1997), Borkovec and Ruscio (2001), Dugas and Robichaud (2007), Heimberg et al (2004), Leichsenring et al (2010), Ladouceur et al (2007), Linden et al (2005), Warner et al (2009), Haby et al (2006), that reported the effectiveness of CBT on anxiety in patients with psychological disorders like GAD. These studies have been shown improvements in symptoms of GAD.

Psychological problems such as anxiety and depression can decrease the QOL. Therefore the techniques which affect and decrease these psychological problems can improve the QOL.

In this research CBT techniques such as relaxation, systematic desensitization, cognitive restructuring, interpersonal skills, problem solving helped patients to have a better copy with their disorder. For example cognitive exercises such as observing the association between worried thoughts, mood and behavior, the distortions and biases in the way an individual interprets events were introduced by the leader and subjects had the opportunity to practice the techniques in the form of homework assignments. Cognitive restructuring helped patients to recognize their unhelpful and maladaptive beliefs and thoughts and change them to more acceptable and more adaptive beliefs.

Also subjects were asked to practice the formal relaxation and meditation practices at least 30 min every day and to record their practices. Interpersonal skills and problem solving were applied too. These behavioral practices decreased the severity of somatic symptoms in patients. 


\section{Effectiveness of Cognitive-Behavioral Therapy (CBT) on Quality of Life (QOL) and Worry in Patients with Generalized Anxiety Disorder (GAD)}

With using these cognitive and behavioral techniques patients learned to replace maladaptive coping skills with more adaptive one.

Continues using of CBT techniques after treatment lead to effective therapeutic outcomes at follow up. In total the cognitive and behavioral techniques which were used in this research decrease the anxiety and worry symptoms and improve the QOL in patients with GAD. In general CBT can be applied for the patients with GAD as a useful psychological treatment.

There were some limitations with the present study such as lack of other psychotherapy groups. Also the results are based on a relatively small number of cases and so caution should be used in interpreting the data.

The results of this study appear encouraging and support the continued evaluation of CBT, which should now be compared with other treatments.

\section{REFERENCES}

1. Allgulander, C., Bandelow, B., Hollander, E., Montgomery, S. A., Nutt, D. J., Okasha. A., et al. 2003. WCA recommendations for the long-term treatment of generalized anxiety disorder. CNS Spectr, 8: 53-61.

2. American Psychiatric Association. 2000. Diagnostic and Statistical Manual of Mental disorders, $4^{\text {th }}$ ed. text rev. Washington, DC: American Psychiatric Association.

3. Borkovec, T. D., Newman, M. G., Castonguay, L. G. 2003. Cognitive -behavioral therapy for generalized anxiety disorder with integrations from interpersonal and experiential therapies. CNS Spectr, 8, 382-389.

4. Borkovec, T. D., \& Ruscio, A. M. 2001. Psychotherapy for generalized anxiety disorder. $J$ Clin Psychiatry, 62, 37-42.

5. Brown, T. A., Antony, M. M., \& Barlow, D. H. 1992. Psychometric properties of the Penn State Worry Questionnaire in clinical anxiety. Behav Res Ther, 30, 33-7.

6. Brown, T.A., Barlow, D.H., Liebowitz, M. R. 1994. The empirical basis of generalized anxiety disorder. Am J Psychiatry, 151, 1272-1280.

7. Culpepper, L. 2002. Generalized Anxiety Disorder in Primary Care: Emerging Issues in Management and Treatment. J Clin Psychiatry, 63, 35-42.

8. Clark, D. M. E., Fairburn, C. G. 1997. Science and practice of cognitive behavior therapy:, Oxford, Oxford University Press: 112-121.

9. Dugas, M. J., Robichaud, M. 2007. Cognitive-behavioral treatment for generalized anxiety disorder: From science to practice. New York: Routledge.

10. Faramarzi, M., Kheirkhah, F., Esmaelzadeh, S., Alipour, A., Haji ahmadi, M., Rahnama, J. 2008. Is psychotherapy a reliable alternative to pharmacotherapy to promote the mental 


\section{Effectiveness of Cognitive-Behavioral Therapy (CBT) on Quality of Life (QOL) and Worry in Patients with Generalized Anxiety Disorder (GAD)}

health of infertile women? A randomized clinical trial. Eur J Obstet Gynecol Reprod Biol, 141(1), 49-53.

11. Fava, G. A., Ruini, C., Rafanelli, C., Finos, L., Salmaso, L., Mangelli, L. 2005. Wellbeing therapy of generalized anxiety disorder. Psychother Psychosom, 74, 26-30.

12. Fisher, P. L., \& Durham, R. C. 1999. Recovery rates in generalized anxiety disorder following psychological therapy: An analysis of clinically significant change in the STAI-T across outcome studies since 1990. Psychological Medicine, 29, 1425-1434.

13. Gorman, J. M. 2003. Treating generalized anxiety disorder. J Clin Psychiatry, 64, 2, 2429.

14. Gould, R. A., Otto, M. W., Pollack, M. H., Yap, L. 1997. Cognitive behavioral and pharmacological treatment of generalized anxiety disorder: A preliminary meta-analysis. Behav Ther. 28, 285-305.

15. Gregory, D., Johnston, R., Pratt, G., Watts, M., Whatmore, S. 2009. "Quality of Life". Dictionary of Human Geography, 5th ed. Oxford: Wiley-Blackwell. ISBN 978-1-40513287-9.

16. Haby, M. M., Donnelly, M., Corry, J., Vos, T. 2006. Cognitive behavioral therapy for depression, panic disorder and generalized anxiety disorder: A meta regression of factors that may predict outcome. Aust and N.Z J Psychiatry, (40): 9-19.

17. Heimberg, R. G., Turk, C. L. \& Mennin, D. S. (Eds.). 2004. Generalized Anxiety Disorder: advances in research and practice. NewYork: Guilford Press.

18. Kaviani, H., Ahmadi Abhari, A. 2003. Prevalence of Anxiety Disorders in Tehran City. IJPCP, 8 (3) : 4-11.

19. Kessler, R. C., Walters, E. E., Wittchen, H. U. 2004. Epidemiology. In R. G. Heimberg, C. L. Turk., \& D. S. Mennin (Eds). Generalized anxiety disorder: Advances in research and practice, New York: Guilford.

20. Ladouceur, R., Dugas, M., Freestone, M. H., Leger, E., Gagnon, F., Thibodeau, N. 2007. Efficacy of cognitive behavioral treatment for generalized anxiety disorder: Evaluation in a controlled clinical trial. J Consult and Clin Psychol, 68(6), 975-964.

21. Leichsenring, F., Salzer, S., Jaeger, U., Ka"chele, H., Kreische, R., Leweke, F., Ru"ger, U., Winkelbach, C., Leibing, E. 2010. Short-Term Psychodynamic Psychotherapy and Cognitive-Behavioral Therapy in Generalized Anxiety Disorder: A Randomized, Controlled Trial. $J$ of Lifelong Learning in Psychiatry, 8(1), 66-74.

22. Linden, M., Zabraegel, D., Baer, T. 2005. Efficacy of cognitive behavior therapy in generalized anxiety disorder. psychother and Psychosom, 74, 36-42.

23. Meyer, T. J., Miller, M. L., Metzger, R. L., \& Borkovec, T. D. 1990. Development and validation of the Penn State Worry Questionnaire. Behav Res Ther , 28, 487-495.

24. Molina, S., \& Borkovec, T. D. 1994. The Penn State Worry Questionnaire: Psychometric properties and associated characteristics. In G. C. L. Davey \& F. Tallis (Eds.), Worrying: Perspectives on theory, assessment and treatment. Chichester, England: John Wiley \& Sons. 
25. Najafi, M., Qodspoor, Z., Ahmaditahour-Soltani, M., Poorsina, M. 2014. A Comparison of Brain/Behavioral Systems, and Quality of Life among Patients with Schizophrenia and Bipolar Disorder. Zahedan Journal of Research in Medical Sciences, 16(9), 75-78.

26. Nussbaum, M., \& Sen, A. 1993. The Quality of Life, Oxford: Clarendon Press. Description and chapter-preview links.

27. Palahang, H., Nasr, M., Brahani, M., Shahmohammadi, D. 1996. Epidemiology of Mental Illnesses in Kashan City. IJPCP, 2 (4) :19-27.

28. Roberge, P., Marchand, A., Reinharz, D., Marchand, L., Cloutier, K. 2004. Evaluation Economic for Therapies Cognitive -compartmentaland Troubles Anxious.Psychologies Comedienne, 45, 202-218.

29. Roy-Byrne, P. P., Craske, M. G., Stein, M. B., Sullivan, G., Bystritsky, A., Katon, W., et al. 2005. A randomized effectiveness trial of cognitive-behavioral therapy and medication for primary care panic disorder. Arch Gen Psychiatry , 62, 290- 98.

30. Rygh, J. L., Sanderson, W. C. 2004. Treating generalized anxiety disorder: Evidencedbased strategies, tools, and techniques. New York: Guilford Press.

31. Speilberger, C. D., Gorsuch, R. L., Lushene, R., Vagg, \& Jacobs. 1983. Manual for the state-trait anxiety inventory. Palo Alto, CA: Consulting Psychology Press.

32. Warner, C. M., Reigada, L. C., Fisher, P. H., Saborsky, A. L., Benkov, K. J. 2009. CBT for anxiety and associated somatic complaints in pediatric medical settings: An open pilot study. J Clin Psychol in Med Settings, 16, 169-177.

33. Wells, A., \& Matthews, G. 1996. Modelling cognition in emotional disorder: the S-REF model. Behaviour Research and Therapy, 32, 867-870.

34. Wells, A., \& Carter, K. 1999. Preliminary tests of a cognitive model of generalized anxiety disorder. Behaviour Research and Therapy, 37, 585-594.

35. Yonkers, K. A., Warshaw, M. G., Massion, A. O., Keller, M. B. 1996. Phenomenology and course of generalized anxiety disorder. Br J Psychiatry, 168, 308-13. 